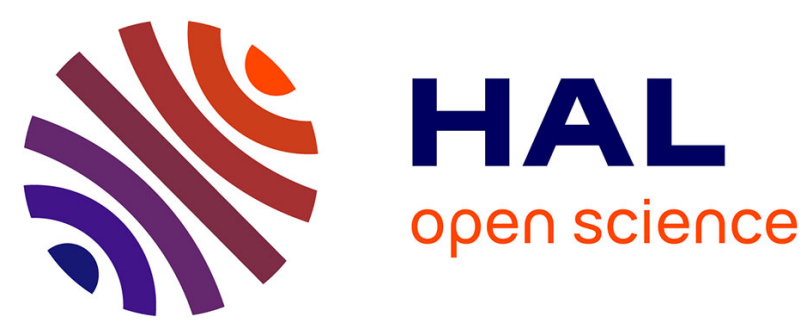

\title{
Engineering of nano-crystalline drug suspensions: Employing a physico-chemistry based stabilizer selection methodology or approach
}

Jean-Rene Authelin, Mostafa Nakach, Jean-René Authelin, Tharwat Tadros, Laurence Galet, Alain Chamayou

\section{To cite this version:}

Jean-Rene Authelin, Mostafa Nakach, Jean-René Authelin, Tharwat Tadros, Laurence Galet, et al.. Engineering of nano-crystalline drug suspensions: Employing a physico-chemistry based stabilizer selection methodology or approach. International Journal of Pharmaceutics, 2014, 476 (1-2), p. 277288. 10.1016/j.ijpharm.2014.09.048 . hal-01593328

\section{HAL Id: hal-01593328 \\ https://hal.science/hal-01593328}

Submitted on 8 Nov 2018

HAL is a multi-disciplinary open access archive for the deposit and dissemination of scientific research documents, whether they are published or not. The documents may come from teaching and research institutions in France or abroad, or from public or private research centers.
L'archive ouverte pluridisciplinaire HAL, est destinée au dépôt et à la diffusion de documents scientifiques de niveau recherche, publiés ou non, émanant des établissements d'enseignement et de recherche français ou étrangers, des laboratoires publics ou privés. 


\title{
Engineering of nano-crystalline drug suspensions: Employing a physico-chemistry based stabilizer selection methodology or approach
}

\author{
Mostafa Nakach ${ }^{\mathrm{a}, *}$, Jean-René Authelin ${ }^{\mathrm{a}}$, Tharwat Tadros ${ }^{\mathrm{b}}$, Laurence Galet ${ }^{\mathrm{c}}$, \\ Alain Chamayou ${ }^{\mathrm{c}}$
}

a Sanofi RED, 13, quai Jules Guesde, Vitry sur Seine 94403, France
b 89 Nash Grove Lane, Wokingham, Berkshire RG40 4HE, UK
'Ecole des Mines d'Albi, Campus Jarlard, Route de Teillet 83013, France

Keywords:

Top down process

Nano-crystalline suspension

Beads milling

Stabilizer

Wetting agent

Dispersant agent

\begin{abstract}
A B S T R A C T
This paper describes a systematic approach to select optimum stabilizer for the preparation of nanocrystalline suspensions of an active pharmaceutical ingredient (API). The stabilizer can be either a dispersant or a combination of dispersant and wetting agent. The proposed screening method is a quick and efficient way to investigate a large number of stabilizers based on the principles of physicalchemistry and employs a stepwise approach. The methodology has been divided in two main parts; the first part being focused on the qualitative screening with the objective of selecting the best candidate(s) for further investigation, the second part has been focused on quantitative screening with the objective to optimize the ratio and amount of wetting and dispersing agents, based on wettability, surface charges measurement, adsorption evaluation, process-ability evaluation and storage stability.

The results showed clearly that SDS/PVP 40/60\% (w/w) (sodium dodecyl sulfate/poly(vinyl pyrrolidone) ) at a total concentration of $1.2 \%$ was the optimum stabilizer composition, at which the resulting nanosuspensions were stable for more than 50 days at room temperature.
\end{abstract}

\section{Introduction}

At present, the small molecular entities produced by the current pharmaceutical discovery are showing an increasing trend toward poor aqueous solubility (Lee, 2002), (Sharma et al., 2009), (Savjani et al., 2012). Such low water solubility is a challenge to achieve adequate bio-availability (Kipp, 2004) after oral administration. It also limits the types of formulations suitable for parenteral administration (Wong et al., 2008). In the recent years, nanocrystalline suspensions have been applied for the delivery of highly water-insoluble active pharmaceutical ingredients (APIs) (Shegokar and Müller, 2010), (Kawabata et al., 2011), (Singh et al., 2011), (Wang et al., 2012). By reducing the particle size of the API, the rate of the dissolution which is directly proportional to the specific surface area, as well as the solubility of the API can be significantly enhanced

\footnotetext{
* Corresponding author. Tel.: +331589321 96; fax: +33158933210. E-mail addresses: mostafa.nakach@sanofi.com (M. Nakach),

Jean-Rene.Authelin@sanofi.com (J.-R. Authelin), tharwat@tadros.fsnet.co.uk (T. Tadros), laurence.Galet@mines-albi.fr (L. Galet), alain.chamayou@mines-albi.fr (A. Chamayou).
}

(Kesisoglou et al., 2007; Noyes and Whitney, 1897). Indeed OstwalFreundlich equation (Borm et al., 2006) shows that the solubility increases exponentially with decrease of particle radius, $r$. Significant increase in solubility is typically observed when $r$ is less than $200 \mathrm{~nm}$. In addition, in contrary to the formulations made from poor tolerable solvents, such as Polysorbate, the injectable dose can be increased using nano-crystalline suspensions. Indeed they are essentially made of pure drug and typically use a relatively small amount of excipients (Bazile, 2011)

Top down process (particles size reduction by milling) is an efficient way to prepare nano-crystalline suspensions. This method is the most commonly used one thanks to the possibility of controlling particles size by a proper choice of wetting/dispersing agent, as well as by controlling the milling conditions (Leena Peltonen, 2010). The generated nano-crystalline particles in the dispersion must be stabilized against flocculation (Holthoff et al., 1996; Lauten and Nystrom, 2001) and crystal growth (Ostwald ripening (Ostwald, 1901)), thus the selection of appropriate stabilizer composition is a crucial step in achieving stable nanocrystalline suspensions.

The present paper proposes a physico-chemistry based method for the selection of suitable wetting/dispersing agent 
for manufacturing nano-crystalline suspensions using top-down process.

\section{Scientific background of formulation strategy}

According to Tadros (2005), in a API powder of any material the aggregates and agglomerates are held together by very strong attractive forces. When these aggregates and agglomerates are dispersed in a liquid medium, the attractive forces are reduced but still sufficient to keep the particles strongly attached together. To separate the particle in such aggregates or agglomerates and to disintegrate them, a combination of milling process and supplementing wetting/dispersant agents is required to overcome such attractive forces.

Depending on both the wetting/dispersant agent used and on the drug material properties, the particle sizes will decrease down to an equilibrium value during milling (water solubility, density, molecular weight). Different drugs will require different wetting/ dispersant agents. Approach for selecting the most suitable wetting/dispersant agent for specific API, is therefore desired.

From our point of view, an ideal wetting/dispersant agent should satisfy several criteria:

(i) It should achieve a maximum reduction in the surface energy of the powder. In fact, Rehbinder and his collaborators investigated the role of surfactants in the grinding process. They found that, as a result of surfactant adsorption at the solid/liquid interface, the surface energy at the boundary is reduced and this facilitates the process of particles deformation or disintegration. The adsorption of surfactants at the solid/liquid interface in cracks facilitates the propagation of this phenomena. This mechanism is referred to as the Rehbinder effect (Monteiro et al., 2013). Furthermore, for an efficient milling, the migration of wetting agent should be as fast as the propagation of cracks (Tadros, 2005).

(ii) The suspension should be stable to avoid Ostwald ripening and flocculation or aggregation during the storage. Typically colloidal stability can be obtained either by electrostatic or steric stabilization or a combination of both: "electrosteric stabilization". Electrostatic stabilization is brought by adsorption of charged species, like ionic surfactant or phospholipids. The efficiency of electrostatic repulsion can be assessed from the knowledge of the ionic concentration and ion valency, as well as by measuring the zeta potential of the particles (Hunter, 1988). It is well known that the electrostatic repulsion increases with a decrease of electrolyte concentration, a decrease of ion valency and an increase of zeta potential (Adler et al., 2000). The zeta potential measurements allow estimating of colloidal suspension stability (Cosgrove, 2010). The colloidal system is stable when a dominant role is played by the forces causing the mutual repulsion of the particles. Higher is the absolute value of the zeta potential, greater is the probability that the studied suspension will be stable. A small value of the zeta potential (from +5 to $-5 \mathrm{mV}$ ) indicates a tendency for the system destabilization (Iwona Ostolska, 2014). Reported typical absolute zeta potential value for stable suspension is between 20 and $30 \mathrm{mV}$, although value as higher as $100 \mathrm{mV}$ can be obtained (Dery, 2012). Non-ionic dispersants reduce flocculation through steric repulsion (Adler et al., 2000). These agents, mostly polymers, form adsorbed layers with thickness $(\Delta)$ which is strongly hydrated in water. When two particles each having an adsorbed layer of thickness $(\Delta)$ approach each other at a surface-to-surface distance $h$ that is smaller than $2 \Delta$, strong repulsion occurs as a result of two phenomena: (i) unfavorable mixing of the stabilizing chains when these are in a good solvent. (ii) Reduction of the configurational entropy on considerable overlap of the stabilizing chains (Fisher, 1958; Sato, 1980).

(iii) Minimizing Ostwald ripening: firstly, in order to limit the material transport, the API solubility should be maintained as low as possible. Indeed, due to Ostwald ripening, the average particle size may increase over time. The driving force for Ostwald ripening is the higher solubility of smaller particles than the larger ones (Hiemenz, 1997). This results in a shift of the particle size distribution to larger values during the storage of nanosuspension, especially at higher temperatures. Secondly, the adsorption of polymer at the surface of particles may also efficiently inhibit the crystal growth (Simonelli et al., 1970).

(iv) The formulation should be easy to handle and to process in a bead mill, it should in particular not be too viscous. Indeed, rheological parameters are critical during milling (Gordana Matijasic and Glasnovic, 2008). High viscosity may require longer processing time (Lee et al., 2005).

\section{Experimental}

\subsection{Materials}

A model hydrophobic and non ionisable highly insoluble API was obtained from Sanofi and the API was micronized by jet milling before use. The physico-chemical properties of the API are provided in Table 1.

The dispersant/wetting agents used for the investigation and their intended use in suspension stabilization are listed in Table 2 (See Appendix A). Several chemical categories were used (cellulose derivatives, povidones, phospholipides, poloxamers, polyethyleneglycol and derivatives, fatty acids and fatty acid esters, SDS, sodium ployacrylate).

\subsection{Methods}

\subsubsection{Preparation of nanosuspensions}

For the screening of dispersant/wetting agents using low shear milling, a suspension containing $20 \%(\mathrm{w} / \mathrm{w})$ of API, $3 \%(\mathrm{w} / \mathrm{w})$ of dispersant/wetting agents, and $77 \%(\mathrm{w} / \mathrm{w})$ of water for injection (WFI) was prepared. An aliquot of $10 \mathrm{ml}$ of the suspension and $20 \mathrm{ml}$ of Zirconium oxide beads ( $700 \mu \mathrm{m}$ diameter supplied by Netzsch (Germany)) were introduced in $30 \mathrm{ml}$ glass vial. The vial was shaken in orbital roller mill for 5 days at $0.03 \mathrm{~m} / \mathrm{s}$ and at room temperature.

For the assessment of process ability using high shear milling, a suspension containing $20 \%(\mathrm{w} / \mathrm{w})$ of API, $3 \%(\mathrm{w} / \mathrm{w})$ of dispersant/ wetting agents and $77 \%(\mathrm{w} / \mathrm{w})$ of WFI was prepared. An aliquot of $50 \mathrm{ml}$ suspension and $50 \mathrm{ml}$ of Polymill ${ }^{\mathbb{R}}$ Cross-linked Polystyrene beads milling media ( $500 \mu \mathrm{m}$ diameter supplied by Alkermes, Inc., (Waltham, MA, USA) were introduced in a Nano-mill ${ }^{\mathbb{R}} 01$ milling

Table 1

Physico-chemical properties of the API.

\begin{tabular}{lc}
\hline Average particle diameter & $5 \mu \mathrm{m}$ \\
\hline Specific surface area $\left(\mathrm{m}^{2} \mathrm{~g}\right)^{* *}$ & 1.5 \\
Molecular weight $(\mathrm{g} / \mathrm{mol})$ & 497.4 \\
Water solubility $(\mu \mathrm{g} / \mathrm{ml})$ & 0.2 \\
pKa & No pKa \\
Log P & 6.9 \\
Real density $(\mathrm{g} / \mathrm{ml})$ & 1.42 \\
Melting point $\left({ }^{\circ} \mathrm{C}\right)$ & 156.7 \\
\hline${ }^{*}$ P is the partition coefficient between octanol and water. \\
${ }^{* *}$ Measurement is performed using Blaine method (Kaye, 1967$)$.
\end{tabular}


Table 2

List of witting/dispersant agent used for the investigation.

\begin{tabular}{|c|c|c|c|c|}
\hline Chemical category & Material & Supplier & Molar mass & $\begin{array}{l}\text { Expected added value for } \\
\text { stabilization }\end{array}$ \\
\hline \multirow[t]{2}{*}{ Cellulose derivatives } & Hydroxypropyl methylcellulose HPMC (Pharmacoat ${ }^{\mathbb{R}}$ 606) & SEPPIC (France) & $\begin{array}{l}\text { Range: } 10,000- \\
1,500,000\end{array}$ & Steric stabilization \\
\hline & Klucel $^{\mathbb{B}}$ Hydroxypropylcellulose: HPC HF & Hercules (France) & $\begin{array}{l}\text { Average: } \\
1,150,000\end{array}$ & Steric stabilization \\
\hline \multirow[t]{2}{*}{ Povidones } & Luvitec ${ }^{\circledR}$ polyvinylpyrrolidone: PVP (K30) & BASF (France) & Average: 50,000 & Steric stabilization \\
\hline & $\begin{array}{l}\text { PVP-VA (Plasdone }{ }^{\mathrm{TM}} \mathrm{S}-630 \text { ) linear random copolymer of N-Vinyl-2- } \\
\text { pyrrolidone and vinyl Acetate }\end{array}$ & Ashland (France) & Average: 27,000 & Steric stabilization \\
\hline \multirow[t]{3}{*}{ Phospholipids } & $\begin{array}{l}\text { Phosal }{ }^{\mathbb{R}} 50 \text { PG compound of } 50 \% \text { phosphatidylcholine from soybean } \\
\text { with propylenglycol }\end{array}$ & $\begin{array}{l}\text { Phospholipid GmbH } \\
\text { (Germany) }\end{array}$ & 775 & $\begin{array}{l}\text { Electrostatic } \\
\text { stabilization }\end{array}$ \\
\hline & $\begin{array}{l}\text { Phospholipon }{ }^{\mathbb{B}} 90 \text { G Pure phosphatidylcholine stabilized with } 0.1 \% \\
\text { ascorbyl palmitate }\end{array}$ & $\begin{array}{l}\text { Phospholipid GmbH } \\
\text { (Germany) }\end{array}$ & 758 & $\begin{array}{l}\text { Electrostatic } \\
\text { stabilization }\end{array}$ \\
\hline & Lipoid $^{\mathbb{B}}$ S100 phosphatidylcholine from soybean & Lipoid (Germany) & 787 & $\begin{array}{l}\text { Electrostatic } \\
\text { stabilization }\end{array}$ \\
\hline \multirow[t]{2}{*}{ Poloxamers } & $\begin{array}{l}\text { Poloxamer } 188 \text { Pluronic }{ }^{\mathbb{R}} \text { F68 NF PrillBlock copolymers based on } \\
\text { ethylene oxide and propylene oxide }\end{array}$ & BASF (France) & $\begin{array}{l}\text { Range: } 7680- \\
9,510\end{array}$ & Steric stabilization \\
\hline & $\begin{array}{l}\text { Poloxamer 407P luronic }{ }^{\mathbb{B}} \text { F127 NF PrillBlock copolymers based on } \\
\text { ethylene oxide and propylene oxide }\end{array}$ & BASF (France) & $\begin{array}{l}\text { Range: } 9840- \\
14,800\end{array}$ & Steric stabilization \\
\hline \multirow{3}{*}{$\begin{array}{l}\text { Poly-Ethylene-Glycol } \\
\text { \& derivatives }\end{array}$} & Polyethylene Glycol 8000 PEG 8000 & Sigma-Aldrich (France) & Average: 8000 & Steric Stabilization \\
\hline & Solutol ${ }^{\circledR}$ HS 15 Macrogol 15 HydroxyStearate & BASF (France) & 813.2 & Steric stabilization \\
\hline & $\begin{array}{l}\text { Vitamine E TPGS } \\
1000 \text { Succinate) }\end{array}$ & $\begin{array}{l}\text { Eastman Chemical } \\
\text { Company (Netherlands) }\end{array}$ & 1,513 & Steric stabilization \\
\hline \multirow[t]{5}{*}{$\begin{array}{l}\text { Fatty Acids and Fatty } \\
\text { acid Esters }\end{array}$} & Cremophor $^{\bar{B}}$ RH 40 Macrogol-Glycerolhydroxystearate & BASF (France) & $\begin{array}{l}\text { Range: } 300- \\
6,000\end{array}$ & Steric stabilization \\
\hline & Montanov $^{\mathbb{R}} 68$ Cetearyl Alcohol \& Cetearyl Glucoside & SEPPIC (France) & N.A. & Steric stabilization \\
\hline & Montanox $^{\overline{\mathbb{R}}} 80$ Ethoxylated sorbitan ester) & SEPPIC (France) & 1,310 & Steric Stabilization \\
\hline & Gelucire $^{\circledR} 4414$ Lauroyl macrogol-32 glycerides & Gattefossé (France) & N.A. & Steric stabilization \\
\hline & Simulsol $^{\mathbb{R}}$ M49 Polyethoxylated castor oil (PEG-20 stearate) & Seppic (France) & 1,165 & Steric stabilization \\
\hline \multirow[t]{2}{*}{ Others } & Soduim Polyacrylate ${ }^{\bar{R}}$ & BF Goodrich chemical (USA) & 104,400 & $\begin{array}{l}\text { Electrosteric } \\
\text { stabilization }\end{array}$ \\
\hline & Sodium dodecyl sulfate (SDS) & Univar (France) & 288.4 & $\begin{array}{l}\text { Electrostatic } \\
\text { stabilization }\end{array}$ \\
\hline
\end{tabular}

system (Annular mill purchased from Alkermes, Inc., (Waltham, MA, USA), having a stator of $80 \mathrm{~mm}$ diameter and a rotor of $73 \mathrm{~mm}$ ). The mill was operated during $1 \mathrm{~h}$ at $20^{\circ} \mathrm{C}$ and $3 \mathrm{~m} / \mathrm{s}$.

For the optimization of the \% of selected dispersant/wetting agent, a suspension containing $20 \%(\mathrm{w} / \mathrm{w})$ of API, the dispersant/ wetting agents concentration varying between 0.3 and $3 \%(w / w)$ and WFI qs $100 \%(\mathrm{w} / \mathrm{w})$. An aliquot of $50 \mathrm{ml}$ suspension and $50 \mathrm{ml}$ of Polymill $^{\mathbb{R}}$ Cross-linked Polystyrene beads milling media ( $500 \mu \mathrm{m}$ diameter supplied by Alkermes, Inc. (Waltham, MA, USA) were introduced in a Nano-mill ${ }^{\mathbb{R}} 01$ milling system (Annular mill purchased from Alkermes, Inc. (Waltham, MA, USA), having a stator of $80 \mathrm{~mm}$ diameter and a rotor of $73 \mathrm{~mm}$ ). The mill was operated at $20^{\circ} \mathrm{C}$ and $3 \mathrm{~m} / \mathrm{s}$. The milling operation was performed during $105-240 \mathrm{~min}$.

\subsubsection{Characterization}

3.2.2.1. Measurement of specific surface area of API powder. The specific surface area (SSA) of API powder is measured using Blaine apparatus BSA1 supplied by ACMEL, France. The measurement was carried out at room temperature. The SSA was determined based on Kozeny-Carman theory (Rigden, 1947), by measuring the air permeability of compressed powder bed. The relationship between the specific surface area (SSA) and the flow time $(t)$ of a known volume of air in is given by Eq. (1):

$S S A=K \times \frac{\varepsilon^{3 / 2}}{\rho_{S} \times(1-\varepsilon)} \times \frac{t^{1 / 2}}{(0.1 \eta)^{1 / 2}}$ where $K$ is the apparatus constant $\left[\mathrm{g}^{1 / 2} \times \mathrm{cm}^{3 / 2} \times \mathrm{s}^{-1}\right], \varepsilon$ is porosity of the compressed powder bed, $\eta$ is air viscosity (Pa s), $\rho_{\mathrm{s}}$ is the absolute density of the API $\left(\mathrm{g} \times \mathrm{cm}^{3}\right)$ and $t$ is the flow time (s).

3.2.2.2. Suspension particles size measurement. The particles size measurement was performed using two methods:

(i) Dynamic light scattering, referred to as photon correlation spectroscopy (PCS), using Coulter $\mathrm{N} 4{ }^{\circledR}{ }^{\circledR}$ equipment supplied by Beckman coulter (France). The method is based on measuring the intensity fluctuation of scattered light as the particles undergo Brownian diffusion. From the intensity fluctuation, the diffusion coefficient $D$ can be calculated, and from which, the particle radius, $r$, is estimated using the Stockes-Enstein equation (Pecora, 1985). The particle size measurements were carried out using a scattering angle of $90^{\circ}$. The refractive index was fixed at 1.332 . The temperature was fixed at $20^{\circ} \mathrm{C}$. The suspension was diluted from $20 \%(\mathrm{w} / \mathrm{w})$ to $0.1 \%(\mathrm{w} / \mathrm{w})$ with purified water. $10 \mu \mathrm{l}$ of diluted suspension were added to $1 \mathrm{ml}$ of purified water. The resulting suspension was gently mixed in DLS cuvette and then placed into the measuring cell of DLS. The measurement was repeated 3 times.

(ii) Laser diffraction using Malvern Mastersizer $2000^{\circledR}$. This method is based on measurement of angle of light diffracted by the particles, which depends on the particle radius, using Fraunhofer diffraction theory. This method can measure the particle sizes down to $1 \mu \mathrm{m}$. For small particles, forward light scattering is measured with the application of Mie Theory of light scattering. 
By combining the results obtained with light diffraction and forward light scattering, the particle size distributions in the range $0.02-10 \mu \mathrm{m}$ can be measured (Swithenbank et al., 1976).

The Mastersizer is equipped with lens having focal length of $550 \mathrm{~mm}$ and cell measurement having thickness of $2.4 \mathrm{~mm}$. The sample was diluted in $100 \mathrm{ml}$ of purified water and introduced in MS1 sampler. The suspension was stirred at $1500 \mathrm{rpm}$ and recirculated through the measurement cell. The dilution factor was adjusted in order to ensure an obscuration in the range of 2.54.5. The measurements were carried out at room temperature. Each measurement was performed during $20 \mathrm{~s}$ and repeated 3 times. The refractive index of the API and of dispersing were fixed at 1.61 and at 1.33 , respectively.

3.2.2.3. Scanning electron microscopy (SEM) evaluation of suspension. The nanosuspension was diluted 10,000 times using WFI. $1 \mathrm{ml}$ of the obtained suspension was filtered through Isopore ${ }^{\circledR}$ (Polycarbonate) filter having diameter of $13 \mathrm{~mm}$ and porosity of $0.1 \mu \mathrm{m}$ (supplied by Millipore, France). The filter was then rinsed 3 times with $1 \mathrm{ml}$ of WFI for each rinse. The filter was then bonded to an aluminum pad using conductive adhesive on both sides, and subsequently metalized with gold using metallizer Xenosput XE200 Edwards. The gold deposit was approximately $1.5-2 \mathrm{~nm}$ thickness. For an overview and detailed view, nanoparticles were observed at $15 \mathrm{kV}$ using JEOL JSM-6300F ${ }^{\circledR}$ field emission SEM (supplied by SEMtech solution Inc., USA), at several magnifications (X 1000, X 5000, X 10,000 × 20,000).

3.2.2.4. Suspension stability assessment. The short-term stability was monitored by measuring the particle size immediately after milling, after 7 days and after 15 days of storage at ambient temperature.

For the selected formulation, the stability was monitored over 8 weeks at ambient temperature.

3.2.2.5. Zeta potential measurement of suspension. A Zetasizer Nano ZS ${ }^{\mathbb{R}}$ (Malvern, UK), which applies the M3-PALS technique, a combination of laser Doppler velocimetry (LDV) and phase analysis light scattering (PALS), was used for the zeta potential measurements. The equipment employs a He-Ne laser (red light of $633 \mathrm{~nm}$ wavelength) which first splits into two, providing an incident and a reference beam.

From the electrophoretic mobility, $\mu$, zeta potential, $\zeta$, is calculated using the Smoluchowski equation (Hunter, 1988), that is valid when $k \times r \gg>1$ (where $k^{-1}$ is the Debye length and $r$ is the particle radius). In case of small particles and a low electrolyte concentration, the Huckel equation is applicable for the calculation of zeta potential.

The sample to be measured was diluted in purified water to achieve a solid concentration in the range of $0.0001-0.1 \%$. The obtained suspension was introduced in disposable cuvette (DTS1060) and gently mixed. The cuvette was then placed into the measuring cell of the Zetasizer. The dilution factor was checked in order to generate a minimum count rate of 20,000 counts per second. The measurements were performed at room temperature and repeated 3 times.

3.2.2.6. Rheological measurement of unmilled suspension. Study state, shear stress versus shear rate curves, were carried out using HAAKE Viscotester ${ }^{\circledR}$ VT550 supplied by HAAKE (Germany). A concentric cylinder device was used for this measurement. The measurement was carried out at $20^{\circ} \mathrm{C}$. The shear rate was gradually increased from 0 to $1500 \mathrm{~s}^{-1}$ (up curve) for over a period of $2 \mathrm{~min}$ and decreased from 1500 to $0 \mathrm{~s}^{-1}$ (down curve) over another period of $2 \mathrm{~min}$. The test samples were $25 \mathrm{ml}$ of unmilled suspension containing $20 \%$ API (w/w), $3 \%(w / w)$ stabilizer and $77 \%(\mathrm{w} / \mathrm{w})$ of WFI. These samples were homogenized by using an ultra-Turrax ${ }^{\circledR}$ T-8 (supplied by IMLAB France) for $10 \mathrm{~min}$ at $6000 \mathrm{rpm}$. The measurements were performed at room temperature. When it is a Newtonian system, the shear stress increases linearly with the applied shear rate, and the viscosity of the suspension can be obtained from the slope. In this case, the up and down curves coincide with each other. When, it is a nonNewtonian system, the viscosity of the suspension decreases with the applied shear rate. When, it is a thixotropic system, the down curve is below the up curve showing hysteresis. The latter could be assessed by measuring the area under the loop.

3.2.2.7. Surface tension measurement of wetting/dispersant solution. The surface tension $\gamma$ of selected dispersant/wetting agent was measured by using KRÜSS $K 12^{\circledR}$ tensiometer supplied by KRÜSS GmbH (Germany). In these measurements, the Wilhelmy plate method (Biswas and Marion, 2001) was applied under quasiequilibrium conditions. Therefore, the force required to detach the plate from the interface was accurately determined. From the $\gamma$ versus $\log C$, where $C$ is the total surfactant concentration curves, the critical micelle concentration (CMC) was determined. The measurements were carried out at room temperature and repeated 3 times.

3.2.2.8. Evaluation of wetting/dispersant agent. Wetting was assessed using the sinking time test method (Walker et al., 1952), as well as by measuring the rate of penetration of wetting/ dispersant solution through a powder plug based on Washburn method (Aartsen, 1974; Chander and Hogg, 2007). By manual tapping a known weigh of powder was placed in glass tube, inner diameter about $9.8 \mathrm{~mm}$ (see Fig. 1). To ensure a constant packing of the powder, the tube was always filled to the same weight. The lower end the tube was closed with a glass filter. The higher end of the tube was hanging on weighing scale platform (precision of $\pm 0.1 \mathrm{mg}$ ). The mass of the liquid penetrated within the powder plug was measured when the lower end of the tube is placed vertically in the wetting liquid. The experiments were performed at $22 \pm 1^{\circ} \mathrm{C}$. Each experiment was repeated 3 times.

From the slope of the linear relationship between the square penetrated liquid weight and time the wettability factor can be calculated using the following equation:

$H^{2}=\frac{\gamma}{2 \eta} \times C \times R \times \cos \theta \times t$

where $H$ is the height of the liquid penetrated within the powder plug, $\theta$ is the contact angle, $\gamma$ is the surface tension of the liquid, $\eta$ is the liquid viscosity, $R$ is the mean radius of the capillary within the powder plug, $C$ is the tortuosity factor, and $t$ is the time. Since all

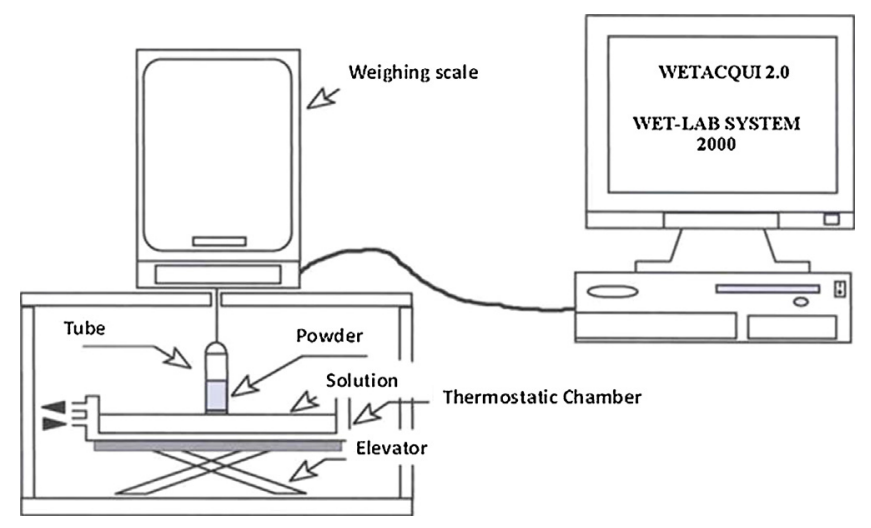

Fig. 1. Experimental setup for studying the wetting of powders. 
powder plugs were prepared at the same compression pressure, the parameter $C$ is assumed a constant.

To calculate $H^{2}$, the relationship of the mass $(m)$ and the height of the liquid penetrated within the powder plug was used. It can be expressed by the following equation:

$m=H \times S \times \varepsilon \times \rho$

where, $m$ is the mass of the liquid penetrated within the powder plug, $H$ is the height of the liquid penetrated within the powder plug, $\rho$ is the volumetric mass of the liquid, $S$ is the surface of the powder plug, and $\varepsilon$ is the fraction of the dead volume of the powder:

Combining Eqs. (2) and (3), the following equation is obtained:

$m^{2}=\frac{\gamma \times \rho^{2}}{\eta} \times \frac{S^{2}}{2} \times C \times R \times \varepsilon^{2} \times \cos \theta \times t$

From a plot of $m^{2}$ versus time (linear curve), the slope $\left(\mathrm{d}\left(\mathrm{m}^{2}\right) /\right.$ $\mathrm{dt}$ ) can be determined and the wettability factor can be calculated from a knowledge of the surface tension $(\gamma)$ and the viscosity $(\eta)$ of the liquid.

The wetability factor can be expressed by the following equation:

$\frac{\mathrm{d}\left(m^{2}\right)}{d t} \times\left(\frac{\eta}{\gamma}\right)=K=\frac{s^{2} \times \rho^{2} \times C \times R \times \cos \theta}{2}$

3.2.2.9. Adsorption isotherm measurement of PVP. The adsorption isotherm of the selected dispersant, namely PVP, was measured at room temperature. Known amounts of the API were introduced in vials at room temperature with various concentrations of PVP solutions. Then, the vials containing the various dispersions were rotated from a few hours to up to $15 \mathrm{~h}$ until equilibrium was achieved. Indeed, it is reported that the intrinsic adsorption kinetic of homopolymer is usually instantaneous (less than $1 \mathrm{~h}$ ) (Dijit and Cohen Sturat, 1992; Somasundara, 2006)
Then the particles were removed from the dispersant solution by centrifugation at $3000 \mathrm{rpm}$ during $20 \mathrm{~min}$. The supernatant was then filtered through $0.45 \mu \mathrm{m}$ PVDF ${ }^{\circledR}$ filter (supplied by Millipore). The dispersant concentration in the supernatant was determined using UV spectrometry by Cary ${ }^{\mathbb{R}} 50$ (UV-vis spectrophotometer supplied by Varian Australia) at $200 \mathrm{~nm}$ wavelength. Each measurement was repeated 3 times. To obtain the amount of adsorption per unit area of the powder $(\Gamma)$, the specific surface area of the powder $(\mathrm{A})$ in $\mathrm{m}^{2} / \mathrm{g}$ was determined using the gas flow method (Blaine).

3.2.2.10. Methodology for selection of wetting/dispersant agent. Nowadays, the general strategy ('fast-to-patient') in pharmaceutical industry is to test a new API in a target patient population as quickly as possible (Pritchard, 2010). The screening methodology, based only on physico-chemistry, would provide a lot of scientific information but would be very time and resources consuming and consequently not aligned with the fast to patient strategy. In contrary, a purely empirical methodology (e.g. design of experiment, trial error approach) may provide a quick solution with poor scientific information. The typical risk of such methodology is that due to the lack of scientific understanding, long term stability or formulation robustness are not anticipated and lead to unfordable formulation development. Our proposal here is to use a compromise between purely scientific and purely empirical methodology in order to achieve both time effectiveness and scientific information.

The proposed screening methodology derived from the previous theoretical considerations was divided in two major parts:

(i) Part 1 focused on qualitative screening to select a lead generation: in this part several screening tests were applied to the mentioned list of wetting/dispersant agents (Table 2 ).

(ii) Part 2 focused on quantitative screening aimed to optimize the selected lead: a customized quantitative optimization of the amount of wetting/dispersant agent, based on wetting, on

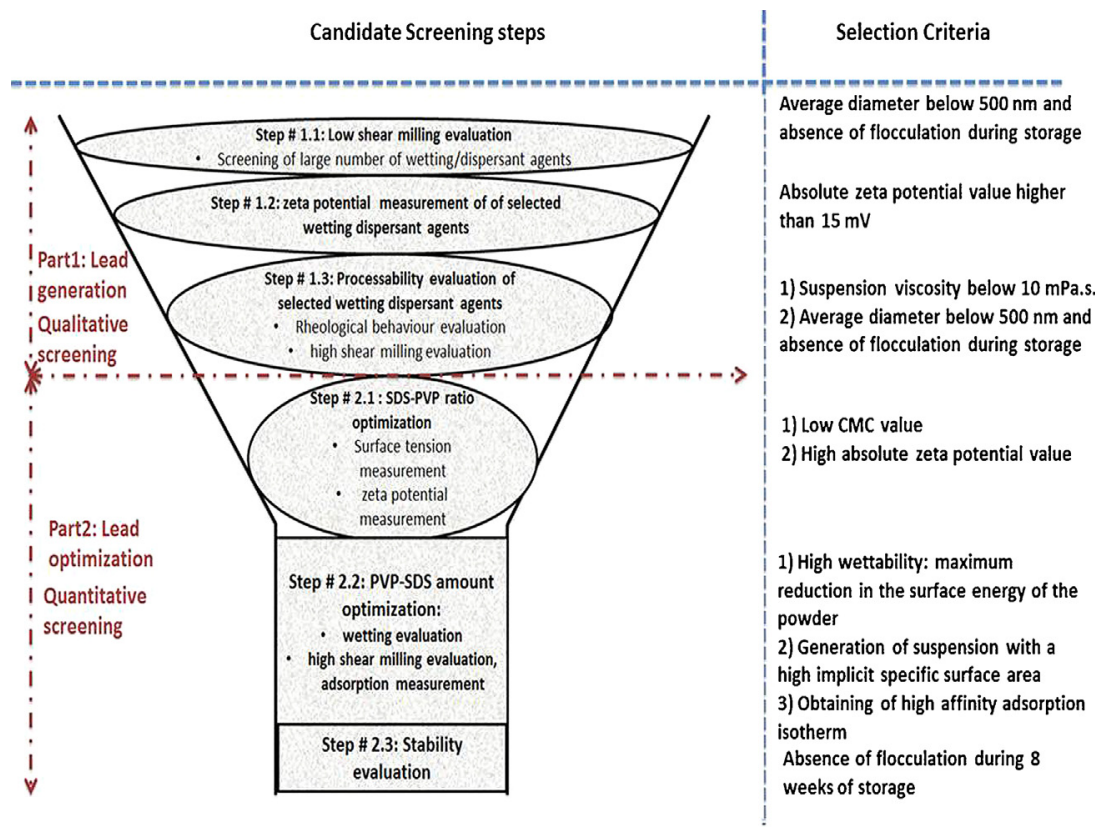

Fig. 2. Illustration of step by step approach methodology for wetting/dispersant agents. 
adsorption and on process-ability. As in the studied case the SDS/PVP association was chosen after Part 1, the PVP and SDS ratio and their amount were optimized.

The tests are summarized in Fig. 2 and described in more details hereafter.

In Part I all tested suspensions contained $20 \%$ of API, which is sufficient from a process productivity point of view, and 3\% of wetting/dispersant agent are used (3\% of wetting/dispersant agent should be sufficient to meet a full coverage of particles having approximately $80 \mathrm{~nm}$ mean diameter assuming a typical adsorption of $3 \mathrm{mg} / \mathrm{m}^{2}$ (Tadros, 2012)). In this part the selection was performed by the following step by step approach:

(i) Step \#1.1: At this step the roller mill is used in order to perform several tests in parallel with a reduced amount of product. Two criteria were used to select the optimum stabilizer. The first criterion is that the API particle mean diameter has to be in the range of $100-500 \mathrm{~nm}$ after milling (typical nanocrystals size (Leena Peltonen, 2010)). The second criterion is that the formulation should be free of flocculation upon at least 2 weeks storage at room temperature. The prepared suspensions were assessed by visual observation, particle size measurement and stability after 2 weeks storage at room temperature.

(ii) Step \#1.2: At this step the measurement of zeta potential of selected samples from step \#1.1 were carried out. To ensure electrostatic repulsion, an absolute value greater than $15 \mathrm{mV}$ was fixed as criterion.

(iii) Step \#1.3: At this step, the process ability of selected samples from step \#1.2 was assessed. This evaluation was done based on the following tests:

a) Step \#1.3a: At this step, the viscosity of unmilled suspension was measured as a function of shear rate as well as of thixotropy. The samples that gave viscosity greater than $10 \mathrm{mPa}$ s at shear rate of $1000 \mathrm{~s}^{-1}$ were excluded. Indeed our internal observations evidenced that this criterion is essential to ensure faster milling kinetics as well as manufacturing-ability at industrial scale.

b) Step \#1.3b: At this step, the milling ability using the high shear mill, namely Nano-mill ${ }^{\mathbb{R}} 01$ milling system of selected samples from step \#1.3a was assessed. This step is essential to ensure the preparation of nanosuspension at industrial scale using high speed milling. All the samples that had particle size greater than $500 \mathrm{~nm}$ or that showed instability due to flocculation or Ostwald ripening were excluded.

From the part I, the combination of SDS/PVP appeared as superior to the other tested agents. Therefore, this combination was selected for further evaluation in the part 2 as described below:

(i) Step \#2.1: At this step the SDS-PVP ratio was optimized. The synergistic effect of the combination was confirmed by performing the following tests:

c) Step \#2.1a: At this step, both surface tension and critical micelle concentration (CMC) of solutions made of SDS-PVP at different ratio were measured. Indeed, Cabane (1977) demonstrated that the poly(ethy1ene oxide) chains are able to capture SDS monomer and micelles. They have shown the existence of an optimal SDS/PEO ratio which maximizes the interaction of both components. The best association can be easily determined by measuring the surface tension.

d) Step \#2.1b: At this step the zeta potential of suspensions made of SDS-PVP at different ratio were measured. (ii) Step \#2.2: At this step, the amount of selected SDS-PVP ratio was optimized. This optimization was done based on the following tests:

a) Step \#2.2a: At this step the wettability of selected SDS-PVP ratio was evaluated in order to select the amount of SDS-PVP allowing a maximum reduction in the surface energy of the powder.

b) Step \#2.2b: At this step, a high shear milling of suspension made of selected SDS-PVP ratio at different amount was evaluated. From this step an optimal amount that gave suspension with a high implicit specific surface area was selected.

c) Step \#2.2c: At this step, the adsorption isotherm of PVP was measured to ensure the strong adsorption of the dispersant (PVP) on the particles surface.

(iii) Step \#2.3:At this step, the physical stability of the selected formulation was evaluated. This was assessed by monitoring the particle size distribution during 8 weeks at room temperature.

\section{Results and discussions}

\subsection{Part 1: Qualitative screening evaluation (lead generation)}

(i) Step \# 1.1: Assessment of milling ability using low shear mill (roller mill).

After roller milling, all samples were inspected for API suspendability. HPC, PEG 8000, Montanov ${ }^{\circledR} 68$ and Sodium polyacrylate ${ }^{\mathbb{R}}$ resulted in an obvious flocculation and in appearance of a 'dry' sample. The particles size of these suspensions was not measured.

The remaining samples were assessed by measuring the particles size at time 0,7 and 14 days. The results are shown in Fig. 3. Suspensions with a particles size greater than $500 \mathrm{~nm}$ and/or showing flocculation after 7 days were not evaluated further. Discarded samples were those made with HPMC, Poloxamer 188 and Poloxamer 407.

(ii) Step \#1.2: Assessment using surface charges measurement (Zeta potential)

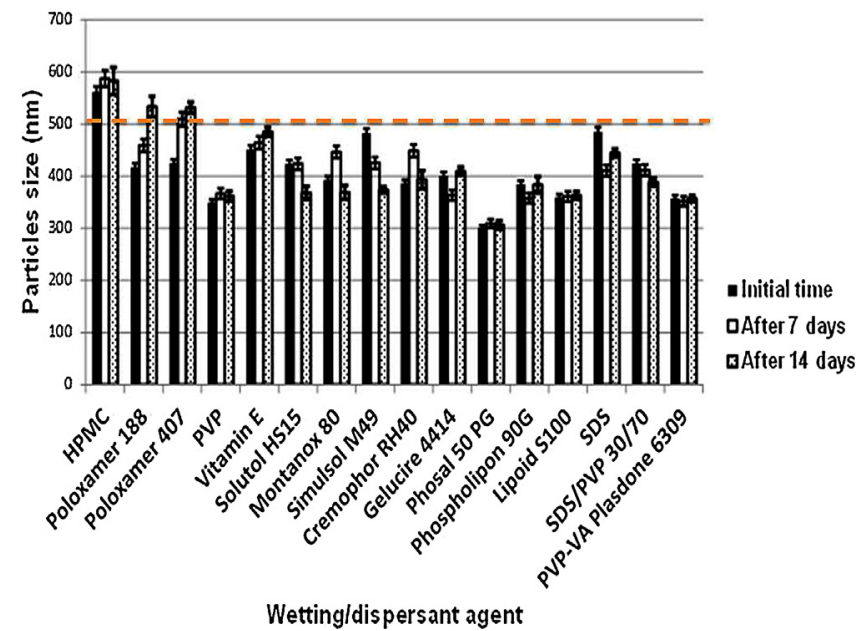

Fig. 3. Low shear milling evaluation using roller mill during 5 days at $0.03 \mathrm{~m} / \mathrm{s}$ and at room temperature. The figure represents the average particles size at initial time, at 7 and at 14 days storage at room temperature (mean \pm S.D, $n=3$ ). 


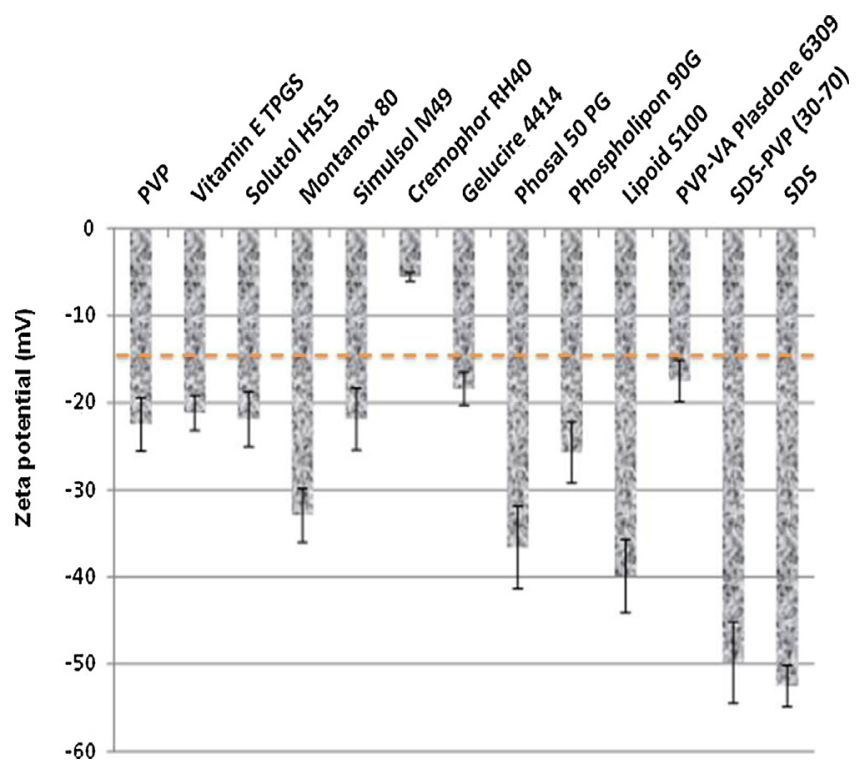

Fig. 4. Results of the zeta potential measurements carried out on selected wetting/ dispersant agents from step \#1.1. Cremophor ${ }^{\mathbb{B}}$ RH40 shows a small value of zeta potential suggesting high risk of nanosuspension destabilization (mean \pm S.D, $n=3$ ).

In the present study, the results of the zeta potential measurements of selected wetting/dispersant agents from step \#1.1 were collected and compared. Fig. 4 shows that all the wetting/dispersant agents, except the Cremophor ${ }^{\circledR}$ RH40, gave an acceptable zeta potential value. One can observe that the charged species (SDS, PVP-SDS) lead to a high absolute value. Therefore, upon this step the Cremophor ${ }^{\circledR}$ RH40 was excluded.

\section{(iii) Step \#1.3 Processability assessment.}

The evaluation of processability was done in two steps: Rheological evaluation to select the wetting/dispersant agents that will promote the milling process and high shear milling ability of suspensions made from selected wetting/dispersant agents to select those that will lead to stable suspension

a) Step \#1.3a: Assessment using the rheological behavior of the suspension (Step \#3a).

Fig. 5 and Fig. 6 show typical flow curves of unmilled suspensions prepared using Solutol ${ }^{\circledR}$ HS15 and Phosal ${ }^{\circledR} 50$ PG.

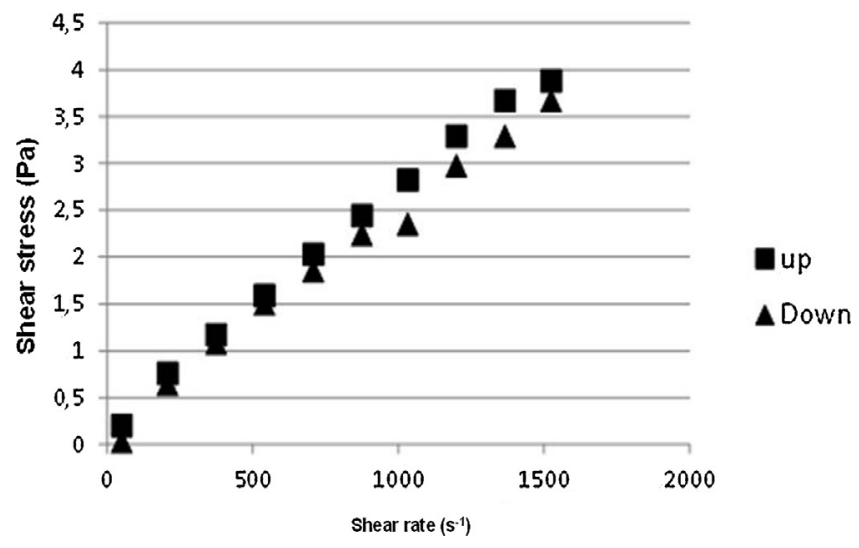

Fig. 5. Flow curves (shear stress as function of shear rate) of unmilled suspension prepared using Solutol ${ }^{\mathbb{B}}$ HS15. The suspension shows Newtonian behaviour with a low viscosity of $2.8 \mathrm{mPas}(n=1)$.

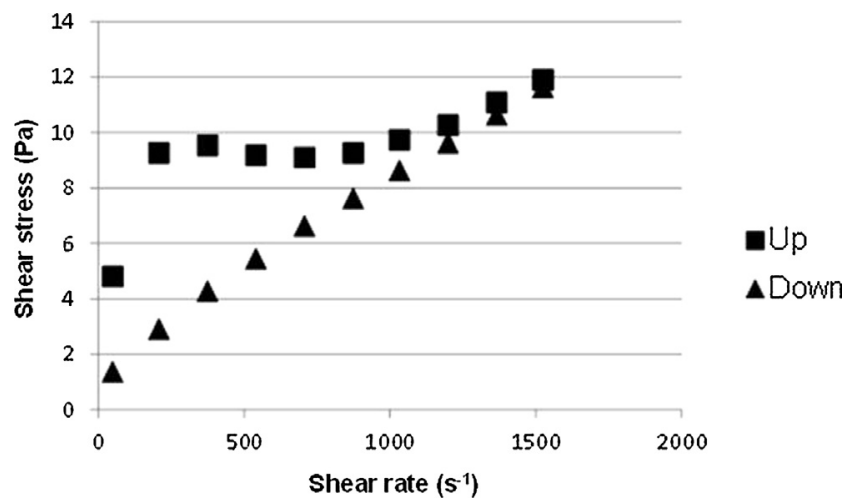

Fig. 6. Flow curves (shear stress as function of shear rate) for unmilled suspension prepared using Phosal ${ }^{\circledR} 50$ PG. The suspension shows non Newtonian behaviour with clear thixotropy, indicating flocculation of the suspension $(n=1)$.

The prepared suspension using Solutol ${ }^{\circledR}$ HS15 shows a Newtonian behavior with a low viscosity of $2.8 \mathrm{mPas}$. In contrast, the suspension using Phosal ${ }^{\circledR} 50$ PG showed a non-Newtonian behavior with a clear thixotropy, indicating a flocculation of the suspension.

The Table 3 summarizes the rheology results of various dispersants. Suspensions with viscosity greater than $10 \mathrm{mPas}$ at high shear rate of $1000 \mathrm{~s}^{-1}$ were excluded from further evaluation. In fact, we have demonstrated that milling a suspension at different viscosity leads to the following observation: higher the viscosity of the suspension, slower is the milling kinetic (unpublished data). This may impact the productivity at industrial scale.

From this step, the suspensions made of Phosal ${ }^{\circledR} 50$ PG, Phospholipon ${ }^{\circledR} 90$ and Lipoid ${ }^{\circledR}$ S100 were excluded.

b) Step \#1.3b: Assessment of milling ability using high shear mill (Nano-mill@ 01 milling system: Step \#3b).

After high shear milling, the suspensions were assessed by measuring the particles size at time 0,7 and 14 days. The results are shown in Fig. 7.

Two systems, SDS/PVP at a ratio of 70/30 and Vitamin E TPGS ${ }^{\circledR}$ provided the highest stabilization of the nano crystalline formulations. These results were confirmed by SEM measurement as illustrated in Fig. 8 for suspensions prepared using SDS/PVP (Fig. 8A) and using Montanox ${ }^{\circledR} 80$ (Fig. 8B). These SEM pictures showed significant differences between the 2 formulations. The needles shaped crystals observed with Montanox ${ }^{\mathbb{R}} 80$ formulation depict an anisotropic crystal growth (Ostwld repining). This is likely linked to preferential adsorption of Montanox ${ }^{\mathbb{R}} 80$ on crystal faces which are parallel to the crystal axis. However, the suspension made of SDS/PVP presents a small, but irregular shaped particles. Furthermore, it can be observed that the particles

Table 3

Summary of rheological results for different dispersant/wetting agents.

\begin{tabular}{ll}
\hline Dispersant/wetting system & Viscosity at $1000 \mathrm{~s}^{-1}(\mathrm{mP})$ \\
\hline Phosal 50 PG & 11 \\
Phospholipon $90 \mathrm{G}$ & 12 \\
Lipoid S100 & 15 \\
Solutol HS15 & 2.8 \\
Vitamine E TPGS & 4.5 \\
PVP & 4.6 \\
SDS-PVP 30/70 & 3.6 \\
PVP/VA & 4.0 \\
Montanox 80 & 2.3 \\
Gelucire 44/14 & 3.4 \\
Simulsol M49 & 2.8 \\
\hline
\end{tabular}




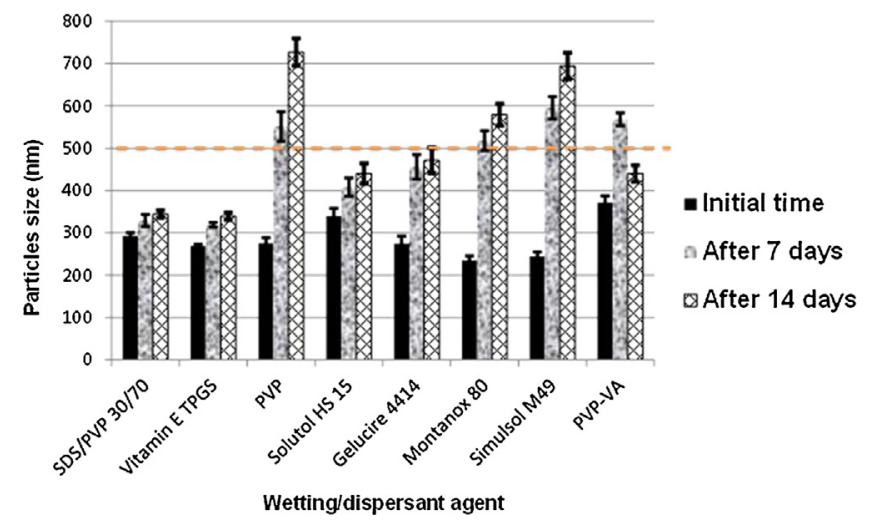

Fig. 7. High shear milling evaluation of using selected wetting/dispersant agents from Step \#1.3a. Milling was performed using Nano-mill ${ }^{\mathbb{R}} 01$ system (Annular mill) at $3 \mathrm{~m} / \mathrm{s}$ and at room temperature. The figure represents the average particles size at initial time, after 7 and 14 days storage at room temperature (mean \pm S.D, $n=3$ ).

size of the suspension using PVP-VA increased from initial time to 7 days and then decreased at 14 days. This may be due to the relaxation of the suspension. Indeed, it was reported for some formulations that when milling is stopped, nanoparticles agglomerated within a few days. The particles size continued to increase until reaching a maximum size. Thereafter, the suspension relaxed spontaneously with an apparent size reduction (Deng et al., 2008)

In summary, PVP alone, Mantanox ${ }^{\circledR} 80$, and Simulsol ${ }^{\circledR}$ M49, as they did not meet the optimization selection criteria, were discontinued from this study.

At the end of this screening part, two formulations are clearly superior: SDS/PVP and Vitamin E TPGS ${ }^{\circledR}$ formulations. In order to illustrate the lead optimization part, the SDS/PVP made from ionic surfactant (SDS) and polymer (PVP) association was considered more relevant. Therefore, it was selected for the second part of the methodology.

\subsection{Part 2: Quantitative screening evaluation (lead optimization)}

In this part, the SDS-PVP ratio is firstly optimized based on both wettability and zeta potential. The amount of SDS-PVP of selected ratio is then optimized to ensure the milling processability and a long term stability under storage conditions.

(i) Step \#2.1: Optimization of PVP-SDS ratio.

a) Step \#2.1a: Surface tension measurements.

Fig. 9 shows the $\gamma$-log C curve for a typical SDS/PVP mixture (20-80\%). This graph shows a typical behavior with $\gamma$ decreasing with $\log C$ increase until the CMC is reached after which $\gamma$ shows only a small decrease with increase of $\log$ C. A plot of CMC versus \%

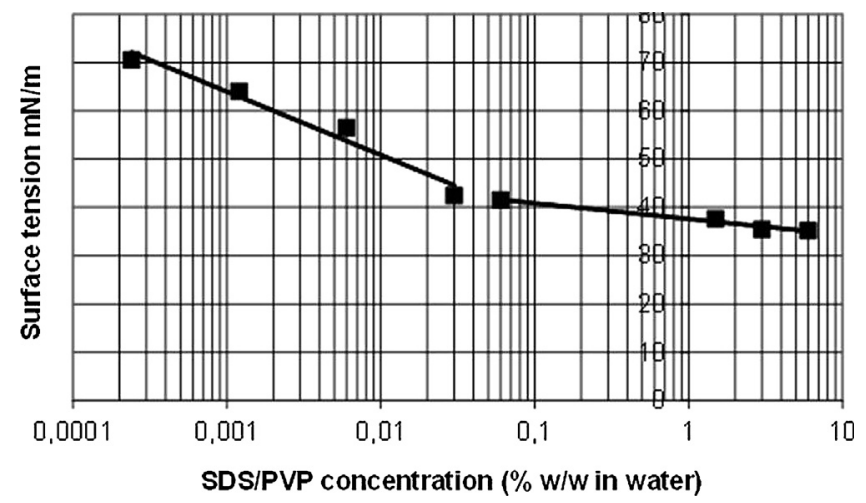

Fig. 9. Surface tension as function of SDS/PVP $(80-20 \% \mathrm{w} / \mathrm{w})$ concentration $(\gamma-\log C$ curve) obtained using Wilhelmy plate method. The addition wetting/dispersant agent decreases the surface tension of the solution, as a function of the total its concentration. Above the critical micelle concentration, no further decrease in surface tension is detected.

of PVP (Fig. 10) in the binary mixture shows a minimum at $60 \%$ of PVP. This result implies a maximum of surface activity at $60 \%$ of PVP in the binary mixture.

b) Step \#2.1b: Zeta potential measurements.

The Fig. 11 outlined that in the absence of SDS, PVP alone results in a low negative zeta potential of $-20 \mathrm{mV}$, which is not sufficient to induce electrostatic stabilization. In this case, the main stability is obtained from a steric repulsion as a result of the adsorbed loops and tails of PVP molecules. Upon addition of SDS, the zeta potential decreased sharply to $-50 \mathrm{mV}$, which likely contributes to the stability through electrostatic repulsion. With further increase of SDS concentration to $40 \%$ (40-60 SDS-PVP), the zeta potential decreased down to $-54 \mathrm{mV}$ and remains almost constant. Thus when using a mixture of SDS and PVP the stabilizing mechanism is a combination of electrostatic repulsion, which shows a maximum energy at intermediate separation distance, and steric repulsion that occurs at shorter distances of separation that is comparable to twice of the adsorbed layer thickness. This combination stabilization mechanism is referred to as electrosteric stabilization (Napper, 1982; Tadros, 1985; Tadros, 1982)

Based on these two evaluations, the SDS-PVP at a ratio of 40$60 \%$ appeared to provide the best association of the two components. Therefore, it was selected for the quantitative optimization.

(ii) Step \#2.2: Amount optimization of PVP-SDS at ratio of $40-60 \%$ $\mathrm{w} / \mathrm{w}$.

(a) Step \#2.2a: Wettability measurements.
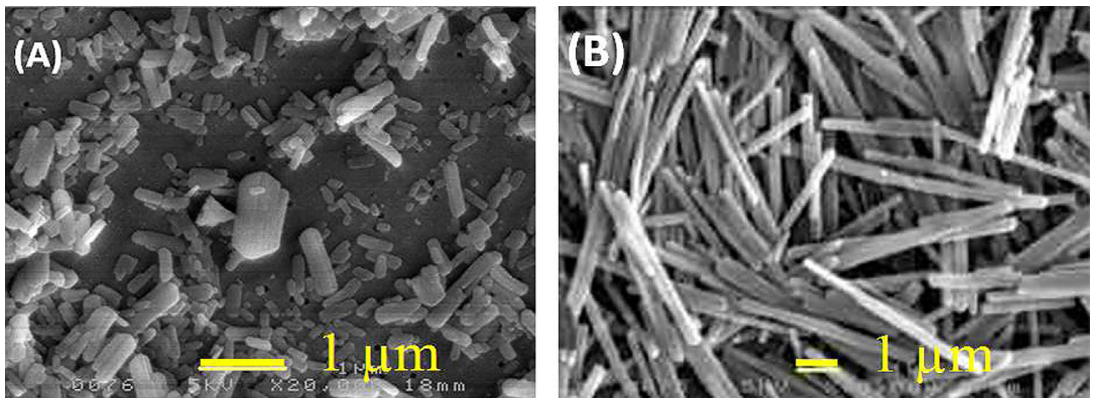

Fig. 8. Scanning electro-microscopy pictures of suspensions produced using PVP-SDS (70/30\% w/w) (A) and Montanox ${ }^{\mathbb{B}} 80$ (B) at $3 \%$ w $/ w$ using Nano-mill ${ }^{\mathbb{E}} 01$ milling system (Annular mill) at $3 \mathrm{~m} / \mathrm{s}$ and at room temperature. 


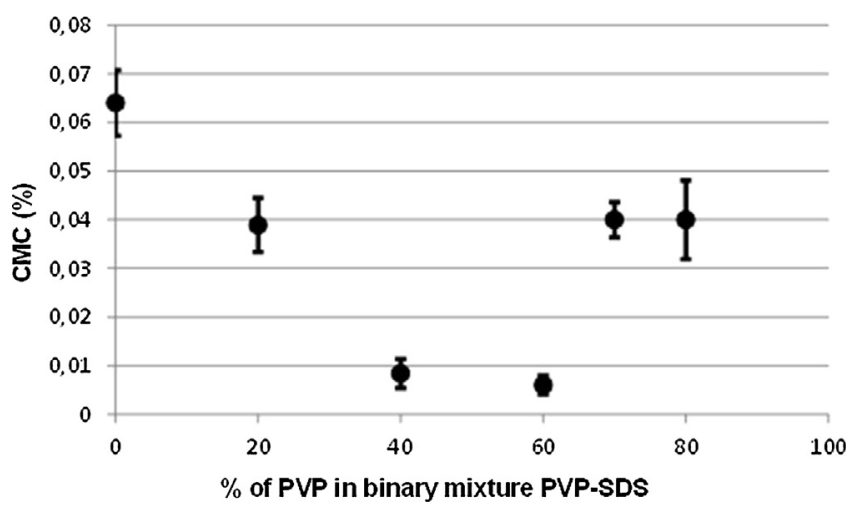

Fig. 10. Critical micelle concentration as function of PVP \% in the binary mixture SDS/PVP. The figure shows a minimum value at $60 \%$ of PVP suggesting a maximum of surface activity of PVP SDS association (mean \pm S.D, $n=3$ ).

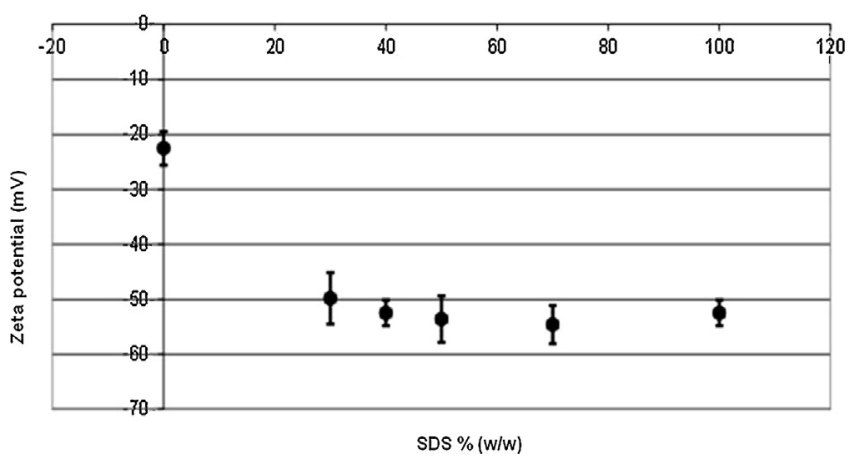

Fig. 11. Zeta potential of the SDS/PVP system as a function of SDS concentration (mean \pm S.D, $n=3$ ). By increasing the SDS concentration, the zeta potential decreased sharply to $-50 \mathrm{mV}$, which likely contributed to the stability through electrostatic repulsion.

Fig. 12 shows the variation of the square of penetrated liquid weight versus time for the $40-60 \%$ (w/w) SDS-PVP system at a total concentration of $1.2 \%$. Fig. 13 shows a plot of wettability factor $K$ versus SDS-PVP concentration. For comparison, the results obtained using SDS alone are shown in the same graph (triangle scatter). It can be seen on Fig. 13 that $K$ increases with increase of surfactant concentration, reaching a plateau at a certain surfactant concentration. For the SDS/PVP system, this plateau is reached at $1.2 \%$ consisting of $0.72 \%$ PVP and $0.48 \%(\mathrm{w} / \mathrm{w})$. Using the same concentration of SDS alone $(0.48 \% \mathrm{w} / \mathrm{w})$, the $K$ value was found to

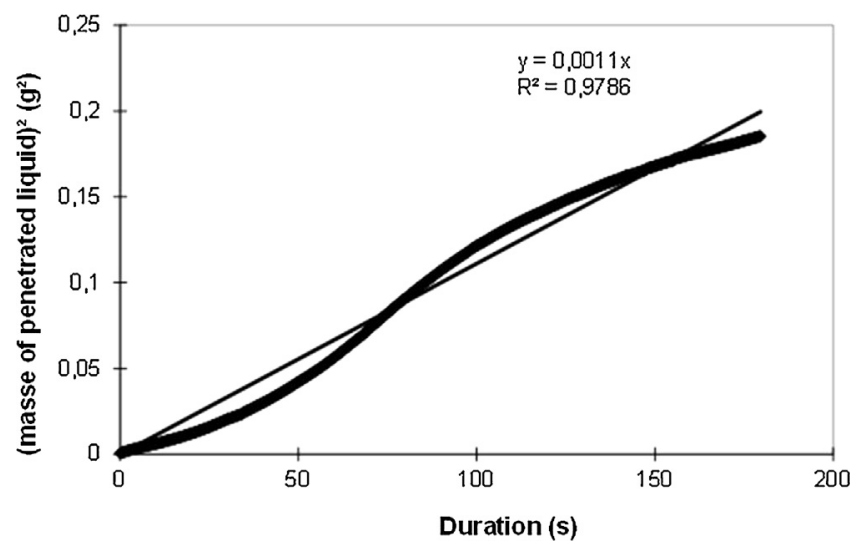

Fig. 12. Liquid penetration rate of SDS/PVP $(40-60 \% \mathrm{w} / \mathrm{w})$ mixture at total concentration of $1.2 \%$. A linear relationship is observed between the square penetrated liquid weight and time. From the slope of the line, a wettability factor $(K)$ can be obtained.

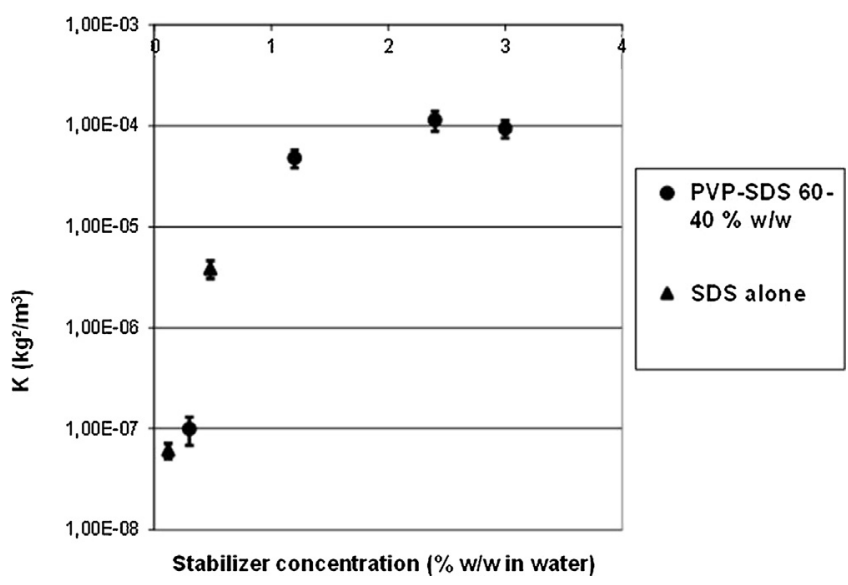

Fig. 13. Wet-ability factor as function of stabilizer concentration of SDS/PVP binary mixture and SDS alone. For the SDS/PVP system, this plateau is reached at $1.2 \%$ consisting of $0.72 \%$ PVP and $0.48 \%(w / w)$ (mean \pm S.D, $n=3$ ).

be much lower than that obtained with the combination system. This clearly demonstrates the synergistic effect obtained when a polymer surfactant mixture is used. The latter is much more effective wetting system as compared to individual components. By using $1.2 \%$ of SDS-PVP at the ratio of $40-60 \%$, maximum reduction in surface energy can be expected for the powder-liquid interface, which will lead to an enhanced cracks propagation (Rehbinder effect), and an enhanced breakage of the particles upon wet milling process.

(b) Step \#2.2b: Milling ability as function of \% of PVP-SDS at ratio of $60-40 \%(w / w)$.

The milling ability was investigated using a kinetic experiment where the reduction in particles size, or the equivalent increase in implicit specific surface area, was measured as function of milling time. A typical result is illustrated in Fig. 14 using 1.2\% w/w PVPSDS at the ratio of $40-60 \%$. The results obtained show an exponential increase in the implicit specific surface area (or decrease in particle sizes) reaching a steady state value at $100 \mathrm{~min}$ of milling. The results can be represented by the following equation:

$\frac{6}{d_{50}}=\left(\frac{6}{d_{50}}\right)_{\infty} \times\left(1-e^{-t / \tau}\right)$

where, $6 / d_{50}$ is the implicit specific surface area, $d_{50}$ is the mean particles diameter at time $t,\left(\mathrm{~d}_{50}\right)_{\infty}$ is the mean particles diameter steady state value over time, $\left(6 / d_{50}\right)_{\infty}$ is the implicit specific surface

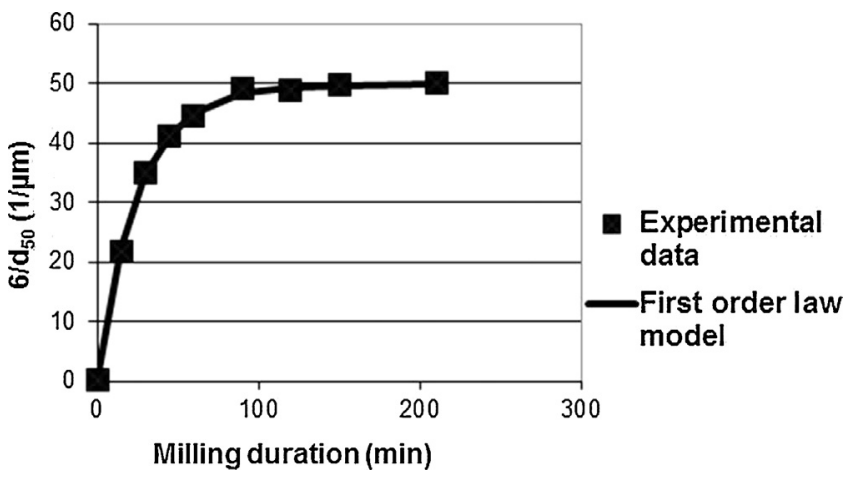

Fig. 14. Milling kinetic of suspension using SDS/PVP $(40-60 \% \mathrm{w} / \mathrm{w})$ at total concentration of $1.2 \%$. The milling kinetic is illustrated by an exponential increase in the implicit specific surface area reaching a steady state value at $100 \mathrm{~min}$ of milling. 


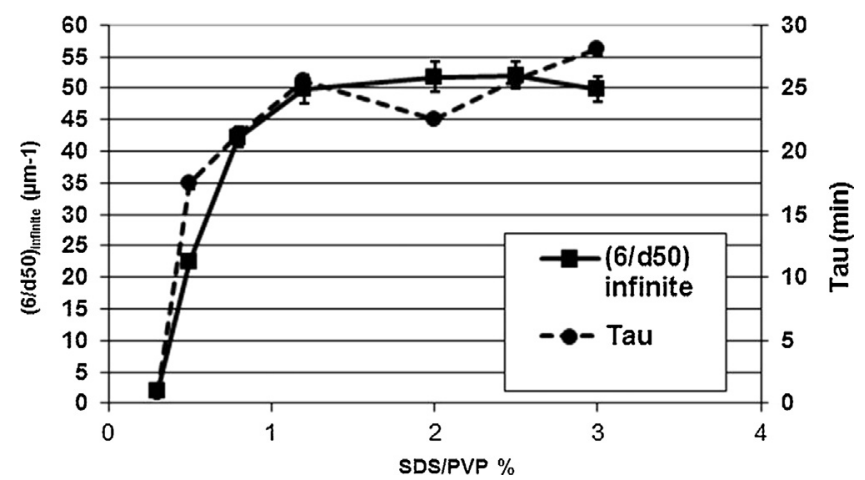

Fig. 15. Infinite implicit surface specific area $\left(6 / d_{50}\right)_{\infty}$ and characteristic time $(\tau)$ as function of stabilizer (SDS/PVP $(40-60 \% \mathrm{w} / \mathrm{w})$ ) concentration. A steady state value over concentration value is observed starting from 1 to $1.2 \%(\mathrm{w} / \mathrm{w})($ mean $\pm S . D$, $n=3)$.

area steady state value over time and $\tau$ is the duration to reach $63 \%$ of the maximum specific surface area. Values for $\left(6 / d_{50}\right)_{\infty}$ and $\tau$ were generated at various stabilizer concentrations and the results are shown in Fig. 15. These results show an initial increase in $\left(6 / d_{50}\right)_{\infty}$ and $\tau$ with increasing stabilizer concentration reaching a plateau at $1-1.2 \%$, and are consistent with those obtained from the wettability evaluation. The results show the existence of two distinct regimes. Below $1-1.2 \%$, the $\left(6 / d_{50}\right)_{\infty}$ increases dramatically when the concentration of SDS-PVP is increased. In contrast, above $1-1.2 \%$, a plateau $\left(\left(6 / d_{50}\right)_{\infty}=50\right.$ corresponding to $d_{50}$ of $\left.120 \mathrm{~nm}\right)$ is reached. A similar behavior was observed when manufacturing submicron emulsion using high pressure homogenization (Laurent Taisne, 1996). The proposed mechanism is that at low stabilizer concentration "poor regime", the particles size is limited by the stabilizer amount corresponding to full coverage. At high stabilizer concentration "rich regime", the particles size is limited by the mechanical energy of milling system. The excess of stabilizer will accumulate in the supernatant phase. This demonstrates that $1-1.2 \%$ is sufficient to ensure the suspension stabilization. Any excess is undesired as it may increase micellar solubility and therefore promote Ostwald repining

(c) Step \#2.2c: Adsorption isotherm measurement of PVP.

Fig. 16 shows the adsorption isotherm of PVP on the API powder surface. As indicated by the complete adsorption of the first added PVP molecules, the results show a high affinity type isotherm. The great deal of scatter obtained at high PVP concentration is likely

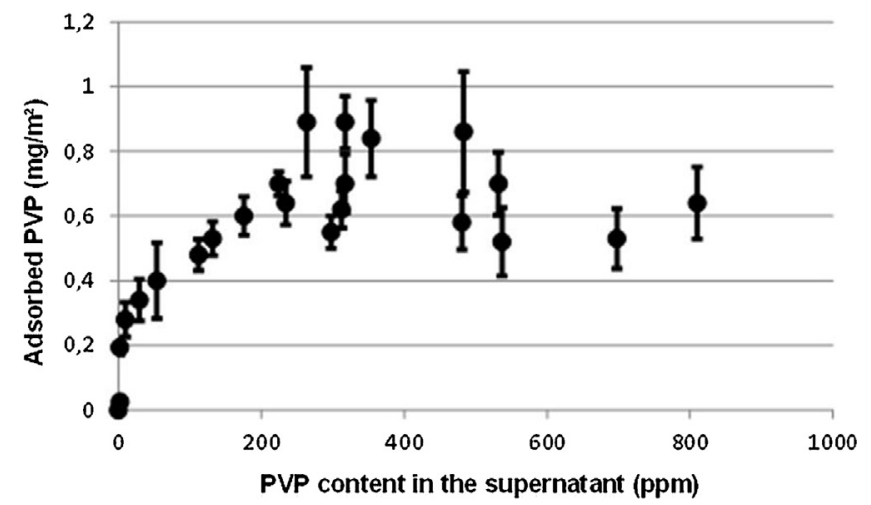

Fig. 16. Adsorption isotherm (high affinity) of PVP at room temperature. A plateau value appeared at approximately $0.7 \mathrm{~m}^{2} / \mathrm{g}$ (mean \pm S.D, $n=3$ ).

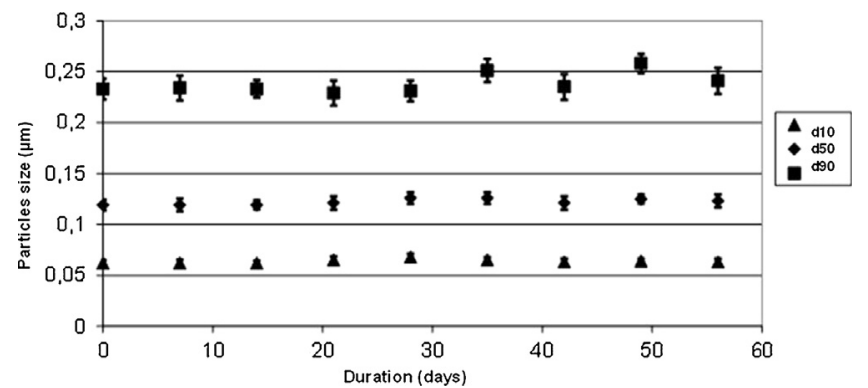

Fig. 17. Stability at room temperature of nano-crystalline suspension stabilized with SDS/PVP $(40-60 \% \mathrm{w} / \mathrm{w})$ at total concentration of $1.2 \% \mathrm{w} / \mathrm{w}$. variation of $d_{10}, d_{50}$ and $d_{90}$ with storage duration. Not significant change is observed (mean \pm S.D, $n=3)$.

due to the variability of the UV method used for determining the remaining PVP concentration. At high PVP concentration, the instrument measures the difference between large quantities, and any uncertainty in the estimated concentration using the UV method can therefore result in a large error in the amount of adsorbed PVP. Hence it is difficult to ascertain an exact plateau value of the isotherm which appeared as between 0.6 and $0.9 \mathrm{mg} /$ $\mathrm{m}^{2}$. Assuming a plateau value of $0.7 \mathrm{mg} / \mathrm{m}^{2}$, the required concentration of PVP to completely saturate the particles can be roughly estimated. From Fig. 14 the smallest particles diameter obtained is about $120 \mathrm{~nm}$. This gives a specific surface area of $35.2 \mathrm{~m}^{2} / \mathrm{g}$. For a $20 \%$ suspension the total surface area was calculated by using the following equation and estimated as $704 \mathrm{~m}^{2}$ :

$$
\times 20 / \rho \times d_{50}
$$

The total surface area coverage required $493 \mathrm{mg}$ or $0.493 \%$ of PVP which corresponds to $0.82 \%$ of SDS/PVP $40-60 \% \mathrm{w} / \mathrm{w}$. These results are within the order of magnitude of the values obtained in milling ability and wettability tests.

\section{(iii) Step \#2.3: Stability results of selected formulation.}

Using the optimum SDS/PVP ratio of 40-60 at a concentration of $1.2 \%$, the stability data were obtained by assessing the particles size as a function of time at room temperature (for the $20 \% \mathrm{w} / \mathrm{w}$ API nanosuspension). Fig. 17 shows the evolution of $d_{10}, d_{50}$ and $d_{90}$ along a storage period of 57 days. It can be seen that no significant change in particle size occurred during the storage period, further confirming the high colloidal stability of the defined nanosuspension following the developed methodology.

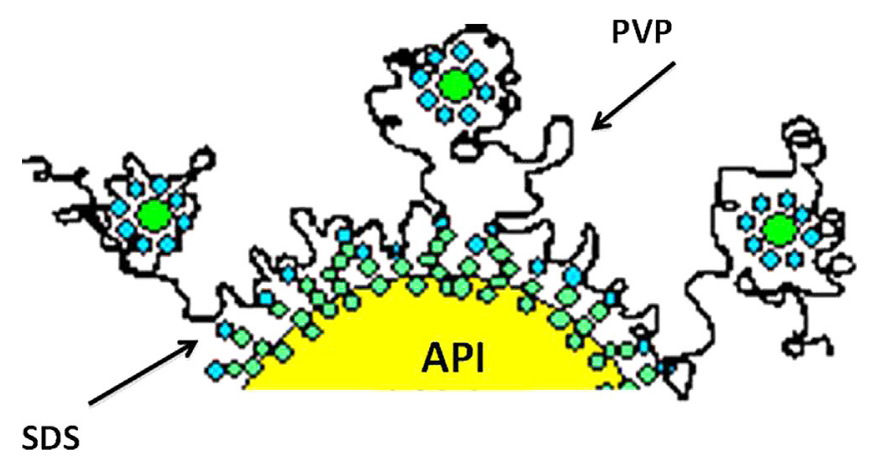

Fig. 18. Schematic of SDS-PVP conformation. 


\section{Discussion}

It is interesting to observe that the selected formulation is a synergic combination of an ionic surfactant (SDS) and a polymer (PVP). Indeed, it achieves a strong electro-steric protection. The trapped SDS micelles by the PVP chains provide a high electrostatic barrier (value) and furthermore the micelles are placed outside the surface of API as illustrated in Fig. 18 (Bernard Cabane, personal communication)

\section{Conclusion}

Using a combination of empirical and colloidal-interfacial fundamental approach, an optimum wetting/dispersant agent was selected for preparing nano-suspensions with a $d_{50}$ lower than $150 \mathrm{~nm}$. Using a systematic approach, a large number of wetting/ dispersant agents was investigated. The unsuccessful agents were excluded following each step. Using a simple milling procedure, namely roller mill combined with particle size measurement, the agents that resulted in a particle diameter greater than $500 \mathrm{~nm}$ or that failed to prevent flocculation were excluded. The remaining agents were further segregated using zeta potential and rheological measurements. Samples that resulted in a low absolute zeta potential value $(<15 \mathrm{mV})$ and a viscosity higher than $10 \mathrm{~m}$ Pa s at a shear rate of $1000 \mathrm{~s}^{-1}$ were also excluded. Among remaining samples, those showing a Newtonian flow were further investigated using high shear milling to select the best wetting/dispersant system. The SDS/PVP mixture was selected for composition optimization using wettability, adsorption isotherm and zeta potential measurement. An optimum stabilizer combination that led to maximum wettability, the best milling results and the maximum stability was identified as SDS/PVP $40-60 \%$ with a total concentration of $1-1.2 \%$. Overall, the present approach of stabilizer selection described in this manuscript is intended to support the formulators to select a suitable wetting/dispersant system for any API to achieve a scalable industrial process leading to stable nanosuspensions.

A step forward would be to introduce additional stress tests to assess the formulation robustness such as thermal stability, freezethawing stability, centrifugation stability, ionic strength impact or effect, and/or a dilution in bio-relevant media.

\section{Acknowledgments}

The authors gratefully acknowledge J.L. Laly (Global Head of Pharmaceutical Sciences Operations at Sanofi R\&D) for his support. The authors also acknowledge Otmane Boussif (Sanofi Pasteur, France), Yan he (LGCR, Sanofi USA), Xavier Pepin and HarivardhanReddy Lakkireddy (LGCR, Sanofi, France) for their contribution to pre-review this manuscript.

\section{Appendix A.}

See Table 2.

\section{References}

Aartsen, B.G.B., 1974. The determination of contact angles of aqueous surfactant solutions on powders. Colloid Polym. Sci. 252, 32-38.

Adler, J., Patist, A., Rabinovixh, Y., Shah, D., Moudgil, B., 2000. Correlation of particulate dispersion stability with the strength of self assembled surfactant films. Langmuir 16, 7255-7262.

Bazile, D., 2011. Nanotechnologies tools in candidate selection for the intravenous route. SMi-8th Conference on Controlled Release, London.

Biswas, S.C., Marion, D., 2001. Interfacial behavior of wheat puroindolines: study of adsorption at the air-water interface from surface tension measurement using wilhelmy plate method. J. Colloid Interface Sci. 244, 245-253.
Borm, P., Klaessig, F.C., Landry, T.D., Moudgil, B., Pauluhn, J., Thomas, K., Trottier, R., Wood, S., 2006. Research strategies for safety evaluation of nanomaterials, part $\mathrm{V}$ : role of dissolution in biological fate and effects of nanoscale particles. Toxicol. Sci. 90, 23-32.

Cabane, B., 1977. Structure of some polymer-detergent aggregates in water. J. Phys. Chem. 81, 1639-1645.

Chander, S., Hogg, R., 2007. Characterization of the wetting and dewetting behavior of powders. KONA 25, 56-75.

Cosgrove, T., 2010. Colloid Science Principles, Methods and Applications, second ed. Wiley.

Deng, Z., Xu, S., Li, S., 2008. Understanding a relaxation behavior in a nanoparticle suspension for drug delivery applications. Int. J. Pharm. 351, 236-243.

Dery, R., 2012. Ceramic Thick Film for Mems and Microdevice. Elsiever Inc..

Dijit, J., Cohen Sturat, M.F., 1992. Kinetic of polymer adsorption in cappilary flow. Macromolecules 25, 5416-5423.

Fisher, E.W., 1958. Elektronenmikroskopische untersuchungen zur stabilität von suspensionen in makromolekularen lösungen. Kolloid-Z 160, 120-141.

Gordana Matijasic, G., Glasnovic, A., 2008. Suspension rheology during wet comminution in planetary ball mill. Chem. Eng. Res. Design 86, 384-389.

Hiemenz, P.C., Rajagopalan, R., 1997. Principles of Colloid and Surface Chemistry, third ed. Marcel Dekker Inc., NewYork, pp. 255-265.

Holthoff, H., Egelhaaf, S.U., Borkovec, M., Schurtenberger, P., Sticher, H., 1996. Langmuir 12, 5541-5549.

Hunter, R.J., 1988. Zeta Potential In Colloid Science: Principles And Applications. Academic Press, UK.

Iwona Ostolska, M.W., 2014. Application of the zeta potential measurements to explanation of colloidal $\mathrm{Cr}_{2} \mathrm{O}_{3}$ stability mechanism in the presence of the ionic polyamino acids. Colloid Polym. Sci.

Kawabata, Y., Wada, K., Nakatani, M., Yamada, S., Onoue, S., 2011. Formulation design for poorly water-soluble drugs based on biopharmaceutics classification system: basic approaches and practical applications. Int. J. Pharm. 420, 1-10.

Kaye, B.H., 1967. Permeability techniques for characterizing fine powders. Powder Technol. 1.

Kesisoglou, F., Panmai, S., Wu, Y., 2007. Nanosizing-oral formulation development and biopharmaceutical evaluation. Adv. Drug Deliv. Rev. 59, 631-644.

Kipp, J., 2004. The role of solid nanoparticle technology in the parenteral delivery of poor water-soluble drugs. Int. J. Pharm. 284, 109-122.

Laurent Taisne, L., 1996. Transfer of Oil between emulsion droplets. J. Colloid Interface Sci. 184, 378-390.

Lauten, R.A., Kjoniksen, A.-L., Nystroem, B., 2001. Colloid Polymer Interactions and Aggregation in Aqueous Mixtures of Polystyrene Latex, Sodium Dodecyl Sulfate, and a Hydrophobically Modified Polymer: A Dynamic Light Scattering Study. Langmuir 17, 924-930.

Lee, J., Lee, S., Choi, J., Yoo, J.Y., Ahn, C.-H., 2005. Amphiphilic amino acid copolymers as stabilizers for the preparation of nanocrystal dispersion. Eur. J. Pharm. Sci. 24, 441-449.

Lee, E.M., 2002. Nanocrystals: resolving pharmaceutical formulation issues associated with poorly water-soluble compounds. In: Marty, J.J. (Ed.), Particles. Marcel Dekker, Orlando.

Leena Peltonen, J.H., 2010. Pharmaceutical nanocrystals by nanomilling: critical process parameters, particle fracturing and stabilization methods. J. Pharm. Pharmacol. 62, 1569-1579.

Monteiro, A., Afolabi, A., Bilgili, E., 2013. Continuous production of drug nanoparticle suspensions via wet stirred media milling: a fresh look at the Rehbinder effect. Drug Dev. Ind. Pharm. 39, 266-283.

Napper, D.H., 1982. Polymeric Stabilization of Colloidal Dispersion. Academic press, London.

Noyes, A.A., Whitney, W.R., 1897. The rate of solution of solid substances in their own solutions. J. Am. Chem. Soc. 19, 930-934.

Ostwald, W., 1901. Uber die vemeintliche isomerie des roten und gelben quecksilberoxyds und die oberflachen-spannung fester korper. Zeitschrift fur Physikalische Chemie 34, 495-512.

Pecora, R., 1985. Dynamic Light Scattering: Applications of Photon Correlation Spectroscopy. Springer.

Pritchard, J.F., 2010. Fast-to-patient: creative strategies for quick demonstration of clinical proof-of-concept. Regul. Rapporteur 7, 7-10.

Rigden, P., 1947. The specific surface of powders. A modification of the theory of the air-permeability method. J. Soc. Chem. Ind. 66, 130-136.

Sato, T., 1980. Stabilization of Colloidal Dispersions by Polymer Adsorption. Marcel Dekker, Inc., New York.

Savjani, K.T., Gajjar, A.K., Savjani, J.K., 2012. Drug solubility: importance and enhancement techniques. ISRN Pharm. 2012.

Sharma, D., Soni, M., Kumar, S., Gupta, G., 2009. Solubility enhancement-eminent role in poorly soluble drugs. Res. J. Pharm.Technol. 2, 220-224.

Shegokar, R., Müller, R.H., 2010. Nanocrystals: industrially feasible multifunctional formulation technology for poorly soluble actives. Int. J. Pharm. 399, 129-139.

Simonelli, A., Mehta, S., Higuchi, W., 1970. Inhibition of sulfathiazole crystal growth by polyvinylpyrrolidone. J. Pharm. Sci. 59, 633-638

Singh, A., Worku, Z.A., Van den Mooter, G., 2011. Oral formulation strategies to improve solubility of poorly water-soluble drugs. Expert Opin. Drug Deliv. 8, 1361-1378.

Somasundara, P., 2006. Encyclopedia of Surface and Colloid Science. Taylor and Francis Group 3, pp. 1758-1770.

Swithenbank, J., Beer, J., Taylor, D., Abbot, D., McCreath, G., 1976. A Laser Diagnostic Technique for the Measurement of Droplet and Particle Size Distribution. AIAA, Aerospace Sciences Meeting. 
Tadros, Th.F., 1985. In: Buscall, R., Corner, T., Stageman, J. (Eds.), Polymer Colloids. Elsevier Applied Sciences, London.

Tadros, T.F., 1982. Effect of Polymers on Dispersion Properties. Academic press London.

Tadros, T.F., 2005. Applied Surfactants: Principles and Applications. WILEY-VCH Verlag GmbH \& Co. KGaA, Weinheim, Germany.

Tadros, T.F., 2012. Dispersion of Powders in Liquids and Stabilization of Suspensions. WILEY-VCH Verlag GmbH \& Co. KGaA, Weinheim, Germany.
Walker, P., Petersen, E., Wright, C., 1952. Surface active agent phenomena in dust abatement. Ind. Eng. Chem. 44, 2389-2393.

Wang, G.D., Mallet, F.P., Ricard, F., Heng, J.Y., 2012. Pharmaceutical nanocrystals. Curr. Opin. Chem. Eng 1,102-107.

Wong, J., Brugger, A., Khare, A., Chaubal, M., Papadopoulos, P., Rabinow, B., Kipp, J. Ning, J., 2008. Suspensions for intravenous (IV) injection: a review of development, preclinical and clinical aspects. Adv. Drug Deliv. Rev. 60, 939-954. 